\title{
A PROBLEM OF STABILIZATION FOR THE MATHEMATICAL MODEL OF ELECTROHYDRAULIC SERVOMECHANISM WITH CONTROL DELAY
}

\author{
Daniela ENCIU ${ }^{1,2 *}$, Ioan URSU ${ }^{1}$, George TECUCEANU ${ }^{1}$ \\ ${ }^{1}$ National Institute for Aerospace Research "Elie Carafoli” - INCAS, Systems \\ Department
}

Bd. Iuliu Maniu 220, 061126 Bucharest, Romania

${ }^{2}$ Department of Mathematics and Informatics, University Politehnica of Bucharest

Splaiul Independentei 313, 060042 Bucharest, Romania

*Corresponding author: enciu.daniela@incas.ro

\begin{abstract}
A very important component of the flight control of the airplane is the hydraulic servomechanism, which can be mechanical or electrical. In this paper a mathematical model for an electrohydraulic servomechanism (EHS) is proposed. EHS is modeled by a five-dimensional switched nonlinear system of differential equations. The novelty of the paper consists in approaching the presence of time delay in the mathematical model and in the study of the stabilization problem that arises. Since the ESH is an automatic system, there are two possible location of the delay: on state variable or on control variable. A study of the stability in the presence of delay on control will be presented.
\end{abstract}

Key Words: Mathematics, Engineering, Electrohydraulic Servomechanism, Control Delay, LQR Control Law, Stabilization, Numerical Simulation

\section{Introduction}

An airplane features in its structure three primary flight surfaces, the aileron, the elevator, the rudder, which, through their movement, changes the air flow and the pressure on the wings leading to the change of the flight direction of the plane along the axis of rotation (longitudinal, lateral, vertical). Unlike the secondary flight surfaces that are controlled by the pilot via the actuators, the primary surfaces are controlled by the interpolation of some servomechanisms on the transmission line of the control. Surface handling takes place under high pressure conditions at high speeds, resulting in the use of mechanical and electrohydraulic servomechanisms (EHS), which meet these requirements. In this paper the dynamics of EHS with delay on control is studied. The basics of delay differential equations (DDE) with delay have begun since the 1950s, but most are purely mathematical works [1]-[6]. In the present work, a bridge between mathematical theory based on DDE and engineering applications is made. It continues the works of the authors in the field of hydraulic servomechanisms analysis and synthesis [7]-[12].

\section{Mathematical model}

The mathematical model starts from the schematic representation of the electrohydraulic servomechanism, Fig. 1, and is described by the switching type systems of 5 nonlinear delay differentials equations (1)(2), with respect to the sign of the variable $x_{5}$. 


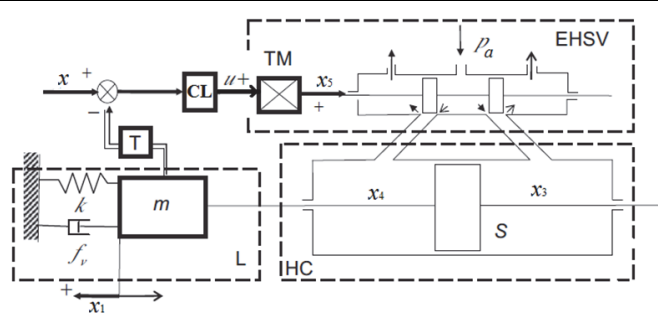

Fig. 1. Drawing of the electrohydraulic servomechanism

The notations refer to: input $u$ (the control variable) and output $y_{0}$. The state variables are: $x_{1}$, the load displacement; $x_{2}$, the load velocity; $x_{3}, x_{4}$ the pressures in the hydraulic cylinder chambers; $x_{5}$, the EHSV spool valve displacement (opening).

$$
\begin{aligned}
& \&=x_{2} ; x_{2}=\left(-k x_{1}-f x_{2}+S x_{3}-S x_{4}\right) / m \\
& \&=\frac{B}{V_{0}+S x_{1}}\left(C x_{5} \sqrt{p_{s}-x_{3}}-S x_{2}-k_{i l}\left(x_{3}-x_{4}\right)\right) \\
& \&=\frac{B}{V_{0}-S x_{1}}\left(-C x_{5} \sqrt{x_{4}}+S x_{2}+k_{i l}\left(x_{3}-x_{4}\right)\right) \\
& \&=-\frac{1}{\tau_{S V}} x_{5}+\frac{k_{S V}}{\tau_{S V}} u_{1}(x(t-h)), C:=c_{d} w \sqrt{2 / \rho} \\
& \&=x_{2} ; \&=\left(-k x_{1}-f x_{2}+S x_{3}-S x_{4}\right) / m \\
& \&=\frac{B}{V_{0}+S x_{1}}\left(C x_{5} \sqrt{x_{3}}-S x_{2}-k_{i l}\left(x_{3}-x_{4}\right)\right) \\
& \&=\frac{B}{V_{0}-S x_{1}}\left(-C x_{5} \sqrt{p_{s}-x_{4}}+S x_{2}+k_{i l}\left(x_{3}-x_{4}\right)\right) \\
& \&=-\frac{1}{\tau_{S V}} x_{5}+\frac{k_{S V}}{\tau_{S V}} u_{2}(x(t-h)) .
\end{aligned}
$$

The involved constants are: $p_{a}$, the supply pressure; $m$, the equivalent inertial load of primary control surface reduced to the actuator $\operatorname{rod} ; f$, the combined coefficient of the damping and viscous friction forces on the load and the cylinder rod; $k$, an equivalent aerodynamic elastic force coefficient; $S$, the effective area of the piston; $k_{i l}$ the coefficient of internal leakages between hydraulic cylinder chambers; $V_{0}$, the cylinder semivolume; $B$, the bulk modulus of hydraulic oil; $\tau_{S V}$, the servovalve time constant; $k_{S V}$ proportionality coefficient relating the input voltage to servovalve to valve displacement; $c_{d}$, the discharge coefficient; $w$, the valve port's width; $\rho$, the hydraulic oil density.
Since the open loop mathematical model of EHS is characterized by a critical stability, an inter-chamber leakage coefficient is introduced [13], in order to make the system stable, otherwise a special treatment with Lyapunov-Malkin theory is necessary [9].

Let us consider a generalized linearized system with delay on control

$$
\begin{gathered}
\boldsymbol{x}(t)=\boldsymbol{A} \boldsymbol{x}(t)+\boldsymbol{B}_{c} u(t-h), \\
u(t)=u_{0}(t+h), \forall t \in[-h, 0), \boldsymbol{x}(0)=\mathscr{X}_{\theta}
\end{gathered}
$$

where $\boldsymbol{A}$ is the Jacobian matrices calculated in zero [14] and $\boldsymbol{B}$ is the control matrix defined by a column vector with the first four elements zero and the fifth element equal with $k_{S V} / \tau_{S V}$. Based on the internal leakage model, the system is stable (matrix $\boldsymbol{A}$ is of Hurwitz type) and the pair $(\boldsymbol{A}, \boldsymbol{B})$ is controllable. Consequently, a control law $u(t)=\boldsymbol{K} \boldsymbol{x}(t)$ can be obtained, in this case by the LQR algorithm, so that the stability of the system is preserved [16]. A predictive type feedback control was chosen [14], [15]

$$
u(t)=\boldsymbol{K}\left(e^{A h} \boldsymbol{x}(t)+\int_{-h}^{0} e^{-A s} \boldsymbol{B}_{c} u(s+t) d s(4)\right.
$$

Two cases were considered: without predictive control (5), and with predictive control (6)

$$
\begin{gathered}
\dot{\boldsymbol{y}}=\boldsymbol{A}_{1} \boldsymbol{y}+\boldsymbol{B}_{c} u(t-h), u=\boldsymbol{K} \boldsymbol{y}(t) \\
\dot{\boldsymbol{y}}(t)=\boldsymbol{A}_{1} \boldsymbol{y}(t)+\boldsymbol{B}_{c} \boldsymbol{K} e^{\boldsymbol{A} h} \boldsymbol{y}(t-h)+ \\
\boldsymbol{B}_{c} \boldsymbol{K} \int_{-h}^{0} e^{-\boldsymbol{A} s} \boldsymbol{B}_{c} u(t+s-h) d s
\end{gathered}
$$

\section{Results and conclusions}

Numerical simulations were performed in MATLAB\&Simulink. The following design data, representing an EHS integrated in the aileron control chain of the Romanian jet fighter IAR99 were considered [7], [9], [10], [12]: $m=60 \mathrm{~kg}, f=3000 \mathrm{Ns} / \mathrm{m}, k=105 \mathrm{~N} / \mathrm{m}$, $S=10^{-3} \mathrm{~m}^{2}, c_{d}=0.6, V_{0}=3 \times 10^{-5} \mathrm{~m}^{3}, p_{s}=$ $2 \times 10^{7} \mathrm{~N} / \mathrm{m}^{2}, B=6 \times 10^{8} \mathrm{~N} / \mathrm{m}^{2}, \rho=850 \mathrm{~kg} / \mathrm{m}^{3}$, $k_{S V}=10^{-4} \mathrm{~m} / \mathrm{V}$, valve port width $w=0.85$ $\mathrm{mm}$, a maximal opening length of rectangular valve port $x_{5 \max }=1 \mathrm{~mm}$ at maximal valve input voltage $\left.u_{\max }=10 \mathrm{~V}\right), \quad k_{i l}=0.04$ $\mathrm{m}^{5} /(\mathrm{Ns})$ and $\tau_{\mathrm{SV}}=1 / 573 \mathrm{~s}$. The equilibrium regime [9] of the mathematical model suffered a perturbation of initial condition type on state $x_{1}, x_{1}(0)=-0.4 \mathrm{~cm}$. 
The representative charts on the comparison between the dynamics of the mathematical model without predictive

$1^{\text {st }}$ case: without predictive control
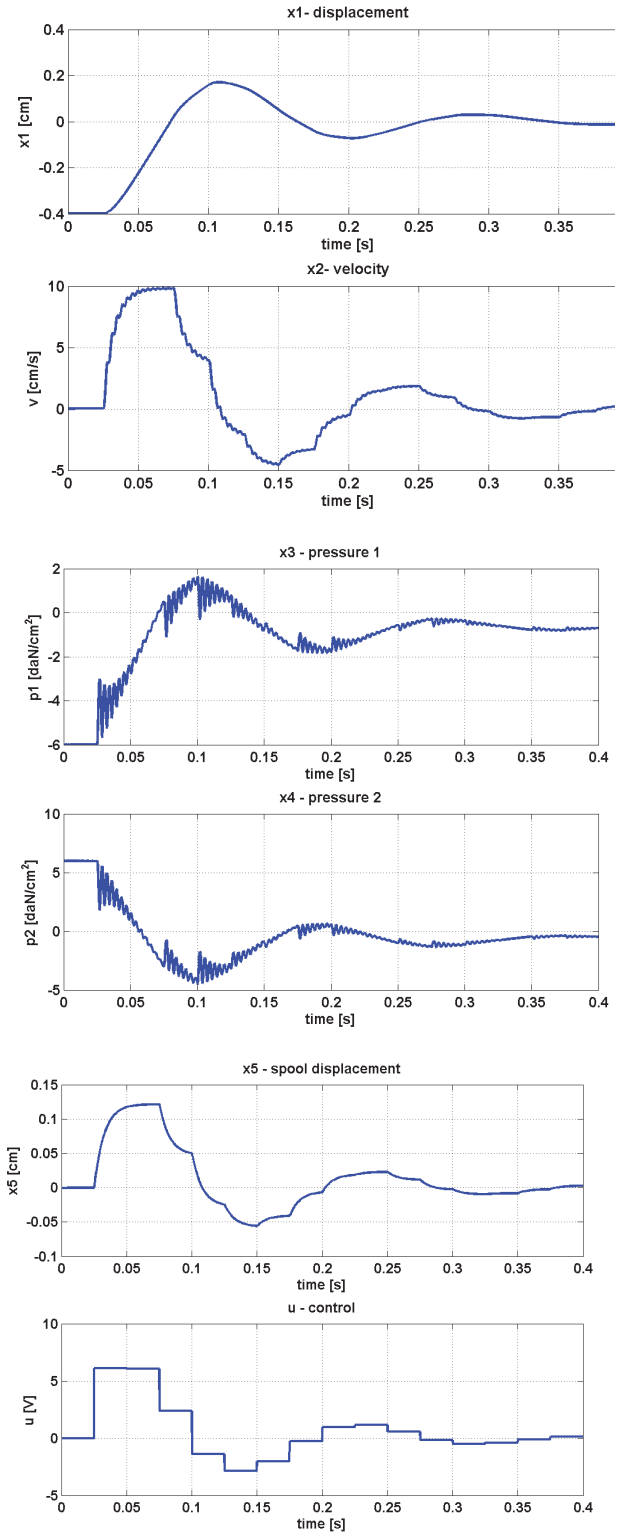

Fig. 2. Comparative results on simu-lation the model without predictive control (left) versus the model with predictive control (right)
The evolution in time of the five state variables the load displacement, the load velocity; the two pressures in the hydraulic cylinder chambers the EHSV spool valve displacement and of the control variable for control and the mathematical model with predictive control are presented in Fig. 2.
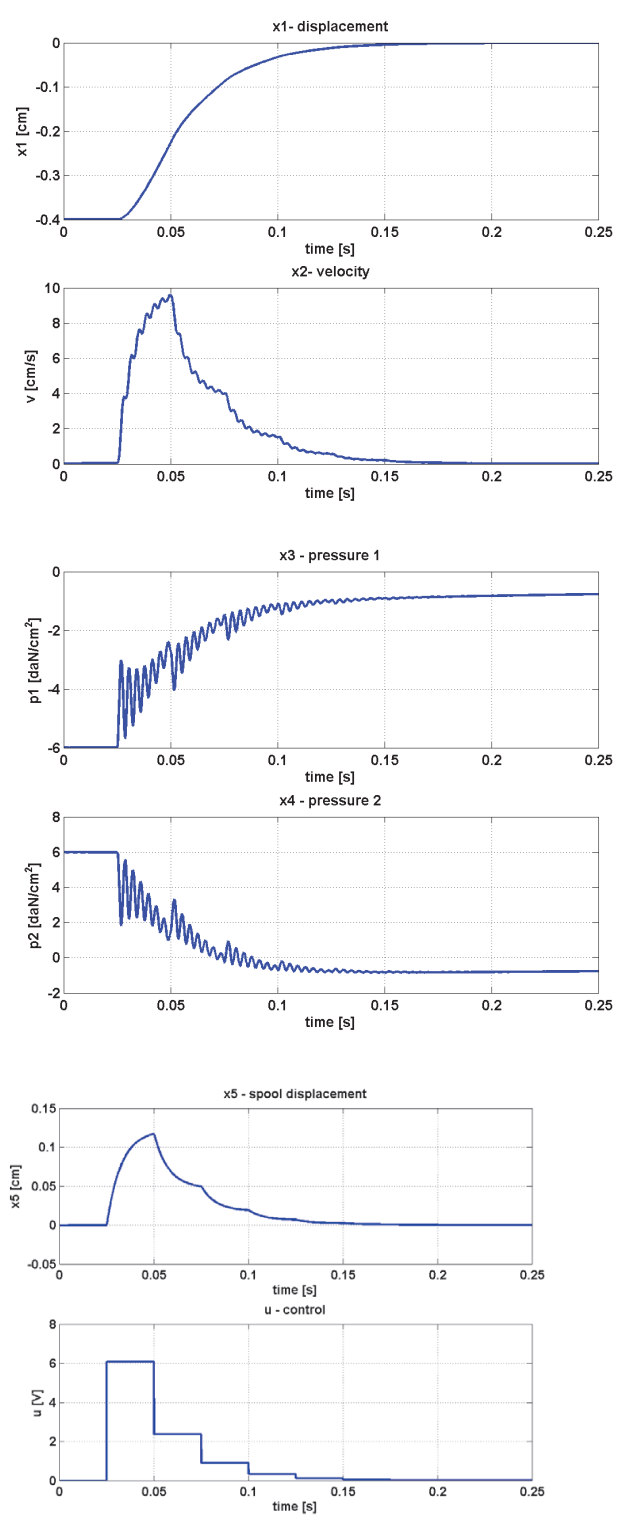

each model is shown. Let remark the net different transient regime of quality variable, the load displacement $x_{1}$, in the two cases. Both systems are stable, but in the first case the system recovers its equilibrium position 
through an oscillating regime and with a time constant of approx. $0.3 \mathrm{~s}$, and in the second case, the transient regime is fast and the time constant is the well known for the hydraulic servomechanism, approx. 0.03 s. Obviously, after stabilization, the control variables in both cases converge to zero. The predictive control performance was thus demonstrated.

\section{Acknowledgment}

This work was supported by a grant of the Romanian Ministry of Research and Innovation, CCCDI - UEFISCDI, project number 87PCCDI/2018, project registration code PN-III-P1-1.2-PCCDI-2017-0868, within PNCDI III.

\section{References}

[1] R. Bellman, K. L. Cooke, Differential difference equation, Academic Press, 1963

[2] K. Gu, V. L. Kharitonov, J. Chen, Stability of Time-Delay Systems, Birkhäuser Basel, 2003

[3] V. L. Kharitonov, Time-Delay Systems. Lyapunov Functionals and Matrices, Birkhäuser Basel, 2013

[4] A. Halanay, Differential equations: stability, oscillations, time lags, Academic Press, 1966

[5] L. E. Elsgolt, S. B. Norkin, Introduction to the theory of differential equations with deviating arguments, Moskow, 1973

[6] V. Rasvan, Absolute stability of feedback control systems with delay (in Romanian), Bucharest, Publishing House of the Romanian Academy RSR, 1975

[7] I. Ursu, F. Ursu, Active and semiactive control (in Romanian), Publishing House of the Romanian Academy, 2002

[8] A. Toader, I. Ursu, Pilot modeling based on time delay synthesis, Proceedings of the Institution of Mechanical Engineers - Part G: Journal of Aerospace Engineering (Proc. IME G J. Aero. Eng.), 228 (2014), No. 5, 740-754 [9] A. Halanay, C. A. Safta, I. Ursu, F. Ursu, Stability of equilibria in a four-dimensional nonlinear model of a hydraulic servomechanism, Journal of Engineering Mathematics, 49 (2004), No. 4, 391-40

[10] A. Halanay, C. A. Safta, F. Ursu and I. Ursu, Stability analysis for a nonlinear model of a hydraulic servomechanism in a servoelastic framework, Nonlinear Analysis: Real World Applications, 10 (2009), No. 2, 1197-1209

[11] A. Halanay, C. A. Safta, A critical case for stability of equilibria of delay differential equations and the study of a model for an electrohydraulic servomechanism, preprint, 2017

[12] I. Ursu, A. Toader, S. Balea and A. Halanay, New stabilization and tracking control laws for electrohydraulic servomechanisms, European Journal of Control, 19 (2013), No. 1, 65-80

[13] H.E. Merritt, Hydraulic control systems, John Wiley \& Sons, New York, 1976

[14] D. Enciu, I. Ursu, G. Tecuceanu, Dealing with input delay and switching in electrohydraulic servomechanism mathematical model, IEEE Xplore, Proc. of CoDIT 2018, in press

[15] D. Enciu, A. Halanay, G. Tecuceanu, I. Ursu, An approach of control delay for electrohydraulic servomechanism, Proc. Of Caius Iacob 2017, in press

[16] H. Kwakernaak and R. Sivan, Linear Optimal Control Systems, 1972, WileyInterscience 